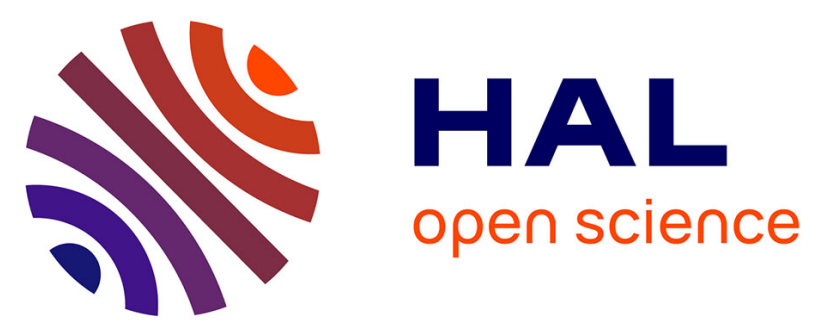

\title{
The use of bootstrapped Malmquist indices to reassess productivity change findings: an application to a sample of Polish farms
}

Kelvin Balcombe, Sophia Davidova, Laure Latruffe

\section{- To cite this version:}

Kelvin Balcombe, Sophia Davidova, Laure Latruffe. The use of bootstrapped Malmquist indices to reassess productivity change findings: an application to a sample of Polish farms. 26. IAAE Annual Meeting: Contributions of agricultural economics to critical policy issues, International Association of Agricultural Economists (IAAE). INT.; European Workshop on Efficiency and Productivity Analysis (EWEPA)., Aug 2006, Gold Coast, Australia. 16 p. hal-02285586

\section{HAL Id: hal-02285586 \\ https://hal.science/hal-02285586}

Submitted on 6 Jun 2020

HAL is a multi-disciplinary open access archive for the deposit and dissemination of scientific research documents, whether they are published or not. The documents may come from teaching and research institutions in France or abroad, or from public or private research centers.
L'archive ouverte pluridisciplinaire HAL, est destinée au dépôt et à la diffusion de documents scientifiques de niveau recherche, publiés ou non, émanant des établissements d'enseignement et de recherche français ou étrangers, des laboratoires publics ou privés. 
The use of bootstrapped Malmquist indices to reassess productivity change findings: an application to a sample of Polish farms

\section{Kelvin Balcombe ${ }^{1}$, Sophia Davidova ${ }^{2}$, Laure Latruffe ${ }^{3}$}

\footnotetext{
${ }^{1}$ University of Reading, Dept of Agricultural and Food Economics, England

${ }^{2}$ Kent Business School, University of Kent, England

${ }^{3}$ INRA, Rennes, France.
}

Corresponding author: Laure Latruffe, INRA - Unité ESR, 4 Allée Bobierre, CS61103, 35011 Rennes Cedex, France, Email Laure.Latruffe@rennes.inra.fr

Contributed paper prepared for presentation at the International Association of Agricultural Economists Conference, Gold Coast, Australia, August 12-18, 2006

Copyright 2006 by Balcombe, Davidova, Latruffe. All rights reserved. Readers may make verbatim copies of this document for non-commercial purposes by any means, provided that this copyright notice appears on all such copies. 


\title{
The use of bootstrapped Malmquist indices to reassess productivity change findings: an application to a sample of Polish farms ${ }^{1}$
}

\begin{abstract}
The paper assesses the extent to which sampling variation affects findings about Malmquist productivity change derived using Data Envelopment Analysis (DEA), in the first stage calculating productivity indices and in the second stage investigating the farm-specific change in productivity. Confidence intervals for Malmquist indices are constructed using Simar and Wilson's (1999) bootstrapping procedure. The main contribution of the paper is to account in the second stage for the information provided by the bootstrap in the first stage. The DEA standard errors of the Malmquist indices given by bootstrapping are employed in an innovative heteroscedastic panel regression, using a maximum likelihood procedure. The application is to a sample of 250 Polish farms over the period 1996-2000.
\end{abstract}

The confidence intervals' results suggest that contrary to what was reported by previous studies, the second half of 1990s for Polish farms was characterised not so much by productivity regress but rather by stagnation. As for the determinants of farm productivity change, we find that the integration of the DEA standard errors in the second-stage regression is significant in explaining a proportion of the variance in the error term. Although our heteroscedastic regression results differ with those from the standard Ordinary Least Squares, in terms of significance (fewer parameters are significant in our heteroscedastic regression) and sign (of the parameter of the share of other income in total income), they are consistent with theory and previous research. Family farms concentrating on farming experienced larger productivity progress than farms with hired labour and income diversification.

Keywords: productivity, Malmquist, bootstrapping, second-stage regression, Poland

\footnotetext{
${ }^{1}$ The authors wish to thank Lech Goraj from IERiGZ in Warsaw for providing access to the data.
} 


\section{Introduction}

The objective of the paper is to assess the extent to which findings about Malmquist productivity change derived using Data Envelopment Analysis (DEA) are affected by sampling variation. Malmquist indices derived with the use of DEA have often been employed for investigating changes in productivity either at farm or sectoral level in agriculture (e.g. Coelli and Rao, 2003; Umetsu et al., 2003). One of the main drawbacks of DEA is that the results may be affected by sampling variation, implying that distances to the frontier are likely to be underestimated.

The issue of sampling variation in DEA models is now receiving increasing attention, following the method introduced by Simar and Wilson (1998, 2000) allowing the construction of confidence intervals for DEA efficiency scores. Their method, relying on resampling the efficiency scores with the help of bootstrapping, has been adapted to the case of Malmquist DEA method (Simar and Wilson, 1999). However, so far there have only been a few empirical applications of bootstrap to Malmquist DEA indices (Tortosa-Ausina et al., 2003; Chen, 2002), none of which are to agriculture.

A few recent studies have investigated productivity change in Polish agriculture. They all computed Malmquist indices, measuring changes in productivity and its components - technical efficiency and technology change (Brümmer et al., 2002; Zawalinska, 2003; Latruffe, 2004; Piesse et al., 2004). All of them suggest some negative trends in productivity in the Polish farming sector. However, none of the studies using DEA accounted for sampling variability by correcting for sample bias, or constructing confidence intervals for the original Malmquist indices. Additionally, they did not attempt to understand the factors behind this negative trend.

This paper, first, estimates Malmquist indices and, second, employs Simar and Wilson's (1999) efficiency bootstrapping procedure adapted to the Malmquist index case. As a result of the 
bootstrap application, a set of bootstrap Malmquist indices is provided. This allows estimating the bias in the results. Confidence intervals are constructed based on the bootstrap sample.

Second, a second-stage regression is performed to investigate factors determining farm productivity change and answer the question why some farms performed better than others. The main contribution of this analysis is that the information provided by the bootstrap procedure is used in this second stage. A heteroscedastic panel regression is employed which utilises the standard errors produced by the bootstrap. Integrating these standard errors into the estimation process should lead to an improvement in efficiency and to more accurate inference regarding the determinants of productivity change. ${ }^{2}$

The paper is structured as follows. The second section describes the methodology, paying particular attention to the heteroscedastic panel regression. Section three discusses the results and section four concludes.

\section{Methodology and data}

\subsection{Malmquist indices and Data Envelopment Analysis}

The Malmquist productivity index, pioneered by Caves et al. (1982) and developed further by Färe et al. (1992) relies on distance functions. The input-orientation Malmquist productivity indices are used in this study. Such orientation is adequate for the sample of Polish farms used here, as under the transition conditions farmers had more control over the reduction of their inputs than over the expansion of their outputs. For each farm, the input-orientation Malmquist productivity index is defined as follows (Färe et al., 1992):

\footnotetext{
${ }^{2}$ The problem of sampling variability in the second-stage regression has also recently been addressed by Simar and Wilson (2005) for efficiency scores. Their procedure, relying on a double bootstrap, accounts for correlation among the DEA estimates but does not make use of the estimates heterogeneity provided by the first-stage bootstrap. While in principle it may be possible to merge the double bootstrap with the approach used herein, the computational requirements might make this impractical.
} 


$$
y_{t}=\left[\frac{d^{t}\left(F_{t+1}, Q_{t+1}\right)}{d^{t}\left(F_{t}, Q_{t}\right)} \frac{d^{t+1}\left(F_{t+1}, Q_{t+1}\right)}{d^{t+1}\left(F_{t}, Q_{t}\right)}\right]^{\frac{1}{2}}
$$

where $\left(F_{t}, Q_{t}\right)$ is the farm input-output vector in the $t$-th period;

$d^{t}\left(F_{t+1}, Q_{t+1}\right)=\max \left\{\delta:\left(F_{t+1} / \delta\right) \in P\right\}$ is the input distance from the observation in the $t+1$

period to the technology frontier of the $t$-th period, with $P\left(Q_{t+1}\right)$ the input set and $\delta$ a scalar.

The indices are calculated with the non-parametric DEA method that uses linear programming to construct a piece-wise frontier that envelops all data points (Charnes et al., 1978). DEA method avoids misspecification errors and allows investigating a multi-output multi-input case simultaneously. The empirical application is to a sample of 250 Polish farms over 5 years, 19962000. Farm level data have been collected by the Institute of Agricultural and Food Economics (IERiGZ) in Warsaw which conducts an annual farm structures survey representative for the bookkeeping farms.

In the model three outputs are included in value terms, crop, livestock and non-agricultural output. Four inputs are used: land, labour, capital and intermediate consumption. Land is defined as the utilised agricultural area (UAA) in hectares, labour is calculated in annual work units $(\mathrm{AWU})^{3}$, capital is proxied by the value of depreciation of fixed assets plus interest paid on loans, and the intermediate consumption includes the aggregate value of seeds, fertilizers, chemicals, feed and fuel. The monetary values for the period 1997-2000 have been deflated, using indices based on 1996 published by the Polish Central Statistical Office (GUS, 2001).

\subsection{Bootstrapping and second-stage regression}

\section{Bootstrapping}

Despite its advantages, the shortcoming of DEA is that the results may be affected by sampling variation in the sense that distances to the frontier are underestimated if the best performers in 
the population are not included in the sample. To account for this, Simar and Wilson (1998, 2000) proposed a bootstrapping method, allowing the construction of confidence intervals for DEA efficiency scores, which relies on smoothing the empirical distribution. The rationale behind bootstrapping is to simulate a true sampling distribution by mimicking a data generating process, here the outputs from DEA. The procedure relies on constructing a pseudo-data set and re-estimating the DEA model with this new data set. Repeating the process many times allows to achieve a good approximation of the true distribution of the sampling (Brümmer, 2001).

Simar and Wilson (1999) adapted the procedure to the case of Malmquist index derived using DEA in order to account for possible temporal correlation arising from the panel data characteristic. They proposed a consistent method using a bivariate kernel density estimate that accounts for the temporal correlation via the covariance matrix of data from adjacent years. The set of bootstrap Malmquist indices provided by this procedure allows to account for the bias and to construct confidence intervals. The final procedure for constructing confidence intervals consists of two main steps. First, a set of bootstrap Malmquist indices is provided. This allows calculating the bias in the results. Second, the confidence intervals are constructed based on the bootstrap sample. In this study, 2000 bootstrap iterations were performed and the 95-percent confidence intervals were constructed. The smoothing bandwidth parameter $(h)$ was determined by an appropriate rule for bivariate data given by Simar and Wilson (1999):

$$
h=\left(\frac{4}{5} n\right)^{\frac{1}{6}}
$$

where $n$ is the number of farms in the sample.

\section{Second-stage regression}

In order to investigate the determinants of farm-specific productivity change, the standard method uses the Malmquist productivity indices as dependent variables in a second-stage regression. This second stage, however, ignores the sampling variability issue. In this study, we propose a heteroscedastic panel regression, using the information provided by the bootstrapping

\footnotetext{
${ }^{3}$ One AWU corresponds to 2,200 labour hours per year.
} 
procedure. This regression relies on maximum likelihood and uses the DEA standard errors of the Malmquist indices. The idea behind our panel estimation is to assume that Malmquist indices are observed with noise:

$$
y_{i, t}=y_{i, t}^{*}+u_{i, t}
$$

with $y_{i, t}^{*}=\gamma_{t} \beta_{0}+x_{i, t}{ }^{\prime} \beta_{1}+e_{i, t}$

where

$y_{i, t}$ is the Malmquist index for the $i$-th farm at the $t$-th period, calculated with DEA and used as the dependent variable in the regression;

$y_{i, t}^{*}$ is the true Malmquist index that is unobserved;

$u_{i, t}$ and $e_{i, t}$ are error terms;

$\gamma_{t}$ is a fixed time effect;

$x_{i, t}$ is a vector of explanatory variables;

$\beta_{0}$ and $\beta_{1}$ are parameters to be estimated.

This delivers the following empirical specification:

$$
y_{i, t}=z_{i, t}{ }^{\prime} \beta+v_{i, t}
$$

with

$$
\begin{aligned}
& z_{i, t}{ }^{\prime}=\left(\gamma_{t}, x_{i, t}{ }^{\prime}\right) \\
& v_{i, t}=e_{i, t}+u_{i, t} .
\end{aligned}
$$

Both $u_{i, t}$ and $e_{i, t}$ are assumed to be normal, independent of the explanatory variables and independent of each other. We assume that $e_{i, t}$ is homoscedastic, but that with the bootstrapping results we have knowledge about the variance of the noise $u_{i, t}$ in the Malmquist indices: 
$\operatorname{Var}\left(v_{i, t}\right)=\theta+\eta_{i, t} \lambda$

where

$\operatorname{Var}\left(e_{i, t}\right)=\theta$

$\operatorname{Var}\left(u_{i, t}\right)=\eta_{i, t} \lambda$

$\eta_{i, t}$ is the variance of the $i$-th farm's DEA Malmquist, as given by the bootstrap distribution;

$\lambda$ is a parameter reflecting the degree to which the bootstrap standard errors contribute to the variance of the errors in equation (5).

In addition, we allow for potential serial correlation between the productivity indices. It is assumed that the $i$-th farm may systematically be above or below its expected growth rate, even after accounting for the impact of the explanatory variables $\left(x_{i, t}\right)$. This is parsimoniously captured by assuming that

$$
\operatorname{Cov}\left(e_{i, t}, e_{i, t-s}\right)=\rho^{s} \theta
$$

where $\rho$ is the parameter which captures potential serial correlation.

The likelihood function to maximise is therefore:

$$
L=\left(\frac{1}{\sqrt{2 \pi}}\right)^{n T} \operatorname{det}\left(\Omega_{v}\right)^{-\frac{1}{2}} \exp \left(-\frac{v^{\prime} \Omega_{v}^{-1} v}{2}\right)
$$

where $n$ is the number of farms and $T$ is the number of periods;

$$
\begin{aligned}
& \Omega_{v}=\theta J(\rho)+\lambda N=\theta[J(\rho)+\tau N] ; \\
& J(\rho)=\left(\begin{array}{cccc}
I & \rho I & \ldots & \rho^{T} I \\
\rho I & I & \cdots & \rho^{T-1} I \\
\cdots & \ldots & I & \ldots \\
\rho^{T} I \theta & \ldots & \rho I & I
\end{array}\right) ;
\end{aligned}
$$

I the identity matrix;

$$
N=\operatorname{diag}\left(\eta_{1}{ }^{\prime}, \eta_{2}{ }^{\prime}, \ldots, \eta_{T}{ }^{\prime}\right) \text {; }
$$


$\tau=\frac{\lambda}{\theta}$

The reparameterisation of the likelihood, to be expressed in terms of $\tau$ and $\theta$ rather than $\lambda$ and $\theta$, facilitates the estimation. This model nests standard sub-models, such as the case where $\tau=0$ and $\rho=0$ that is to say the model reduces to a standard linear regression.

The results of this heteroscedastic panel regression are compared to a standard Ordinary Least Squares (OLS) regression that is usually employed in studies investigating the determinants of productivity change. In addition, the significance of $\tau$ may be examined to determine if the heteroscedastic model is supported by the data.

Seven explanatory variables are used in both second-stage regressions. Land area is included as a farm size indicator. The capital to labour ratio is used as a proxy of farm technology. The share of hired labour represents the farm integration into the labour market. ${ }^{4}$ The availability of financial resources is proxied by the share of marketed output in total output. ${ }^{5}$ The degree of reliance upon and concentration on farming is proxied by the share of other income in total income. Finally, two farmers' characteristics are included, the farmers' age and their agricultural education. The latter is a dummy variable. Four year dummies are incorporated to represent the fixed time effect $\gamma_{t}$.

\footnotetext{
${ }^{4}$ Polish farms are rather small and rely mostly on family labour. They are not well integrated into the factor markets.

5 The mass of Polish farms are semi-subsistence, produce mainly for household consumption and market the surplus. The use of external credit is low and the marketed output is often the single source of cash. For this reason it can be treated as a proxy for liquidity.
} 


\section{Results}

\subsection{Productivity change}

The point estimates of Malmquist indices indicate that over the period 1996-2000 the total factor productivity in Polish agriculture decreased by 2 percent (Table 1). This result is consistent with the results from previous studies. The bias corrected estimates indicate the same direction of change but emphasise stronger the negative trend. In comparison with the point estimates, the regress in productivity appears to be deeper, 4 percent.

The confidence intervals are large, 48 percent on average. This indicates that it is not possible to unambiguously identify farms that have experienced significant progress or regress, namely whose productivity change is significantly different from 0 . Based on the point estimates of Malmquist indices, farms that have experienced productivity progress (that is to say whose Malmquist index is strictly greater than 1) were 128 in 1996/97 (51 percent of the sample), 82 in 1997/98 (33 percent), 76 1998/99 (30 percent) and 176 in 1999/2000 (70 percent). Only between 0 and 3 farms in different years recorded a lack of change in productivity (index equal to 1 ). The remaining farms recorded productivity regress. The picture is not different if the bias corrected point estimates are considered. By contrast, if farms are analysed based on their interval bounds, out of the total sample of 250, 205 farms in 1996/97 (82 percent), 158 in 1997/98 (63 percent), 169 in 1998/99 (68 percent) and 206 in 1999/2000 (82 percent) might have experienced no change in productivity. ${ }^{6}$ Therefore, these results suggest that contrary to what was reported by some previous studies, the second half of 1990s was characterised not so much by productivity regress but rather by stagnation. This is intuitively more appealing as it is difficult to think about factors that would have been responsible for productivity regress even during transition. The

\footnotetext{
${ }^{6} \mathrm{~A}$ farm is said to have experienced significant progress if its confidence interval lower bound is greater than 1, significant regress if its upper bound is less than 1 , and no significant change if 1 is included in its confidence interval.
} 
Polish farming was not subject to such extensive land reforms and farm restructuring as the other countries in transition, and therefore the transitional disruption was not so strong.

From a methodological point of view, this result shows that there is a large uncertainty about the extent of productivity change in Polish farming and strongly supports Simar and Wilson's (1999: 471) argument that "it is not enough to know whether the Malmquist index estimator indicates increases or decreases in productivity, but whether the indicated changes are significant in a statistical sense; i.e., whether the result indicates a real change in productivity, or is an artifact of sampling noise".

\subsection{Determinants of productivity change}

Following the methodology explained above, first, the standard OLS regression was run. The results are presented in Table 2. They indicate that capital to labour ratio, liquidity (the share of marketed output) and other income are significant determinants of productivity change, with the parameter of the capital to labour ratio being negative and the parameter of the other two variables being positive. As for the time trend, year dummies show that the first year of the period recorded the largest increase in productivity. Productivity then dropped, but started recovering again in the last periods.

The results of the heteroscedastic regression are displayed in Table 3. The serial correlation parameter $(\rho)$ is negative, suggesting that farms that increase their productivity in one year tend to move backward in the following year. As for the explanatory variables, two differences with the standard regression results in Table 2 can be noted. First, there is a change in the significance of some parameters. Except for the share of hired labour and year dummies, the parameters present a lower significance. The share of marketed output and the capital to labour ratio are not significant anymore. However, the share of hired labour became significant. It affects negatively the productivity progress. The second difference relates to the sign of the share of other income, namely a switch from a positive sign in the standard OLS regression to a 
negative in the new heteroscedastic regression. The heteroscedasticity parameter $\tau$ is very large (43.6) and its confidence interval does not include 0 , indicating that the heteroscedastic model is supported by the data.

\section{Conclusions}

The analysis of productivity change in Polish agriculture between 1996 and 2000 based on Malmquist DEA point estimates has revealed a gloomy picture. The use of bias corrected indices confirmed this finding as it indicated an average productivity regress of 4 percent. However, the confidence intervals suggest that productivity might have been static rather than decreasing. Therefore, this study underlines the uncertainty surrounding the findings regarding productivity change measured through Malmquist DEA method using point estimates only.

The lack of productivity change in Poland in the second half of 1990's could be attributed to various factors. OECD report on Poland (2004) emphasises the link between land ownership and eligibility for the strongly subsidised farmers social insurance system (the requirement is to keep 1 ha agricultural land to be eligible for the system but to have less than 2 ha to qualify for unemployment benefits) as a critical barrier to productivity growth. The structural inefficiencies are also rooted in the high costs for land registration. In addition, the same report argues that the relative agricultural labour productivity in Poland (measured as agricultural value added per agricultural worker divided by the whole economy value added per one employed) decreased in 1990s. Concerning farm equipment, Zawalinska (2003) reports that between 1995 and 1999 the sales of new farm machineries and implements decreased considerably and physical capital became obsolete. All these factors might have contributed to the stagnation of productivity in Polish agriculture during the period studied.

The novelty of this study is mainly in the second stage where we used a heteroscedastic panel regression estimated by maximum likelihood, that makes use of the bootstrapping information and in particular of the Malmquist indices' standard errors. The heteroscedastic model was 
supported by the data. Additionally, although the inclusion of the information provided by the first-stage bootstrap changed the significance and the sign of some parameters in the secondstage regression, the findings of this regression better meet the a priori expectations based on theory and previous research than the standard ones. The negative influence of the share of hired labour on productivity growth is consistent with the theory, in particular the transaction costs approach. Family labourers are in full control of the resources and technology and, as the only residual claimants, have more incentives than hired labour to act efficiently. Although moving to hired labour involves gains from task specialisation, it may also result in shirking (Allen and Lueck, 1998). Beckmann (1996) argues that due to the high bonding within the family farm, it compares favourably to other forms of capitalist labour organisation of production as it minimises transaction costs.

Concerning the negative impact of the share of other income, most often in transition economies farmers have been pushed to diversify due to declining farm incomes in relative terms. In these circumstances 'push' may be considered as a survival strategy (Chaplin, 2003). However, as it might imply poor management practices and therefore low technical efficiency, such strategy can hardly be favourable to productivity growth.

\section{References}

Allen, D., Lueck, D. 1998. The nature of the farm. Journal of Law and Economics, XLI (October 1998): 343-386.

Beckmann, V. 1996. Transaction costs and institutional choice in agriculture: The example of family vs. hired labour. Paper presented at the VIIIth EAAE Congress, Edinburgh, Scotland, 3-7 September.

Brümmer, B. 2001. Estimating confidence intervals for technical efficiency: The case of private farms in Slovenia. European Review of Agricultural Economics, 28(3): 285-306. 
Brümmer, B, Glauben, T., Thijssen, G. 2002. Decomposition of productivity growth using distance functions: The case of dairy farms in three European countries. American Journal of Agricultural Economics, 84(3): 628-644.

Caves, D., Christensen, L., Diewert, E. 1982. The economic theory of index numbers and the measurement of input, output, and productivity. Econometrica, 50(6): 1393-1414.

Chaplin, H. 2003. Non-Agricultural Diversification of Corporate Farms and Farm Households in Central Europe. PhD Thesis, Imperial College, University of London. Unpublished.

Charnes, A., Cooper, W., Rhodes, E. 1978. Measuring the efficiency of decision making units. European Journal of Operational Research, 2: 429-444.

Chen, S.-N. 2002. Productivity changes in hospitals in Taiwan: A quality incorporated Malmquist index bootstrap approach. Paper presented at the Asia Conference on Productivity Growth, Taiwan, 19-20 July.

Coelli, T., Rao, P. 2003. Total Factor Productivity Growth in Agriculture: A Malmquist Index Analysis of 93 Countries, 1980-2000. Working Paper No. 02/2003, CEPA, University of Queensland.

Färe, R., Grosskopf, S., Lindgren, B., Roos, P. 1992. Productivity changes in Swedish pharmacies 1980-1989: A non-parametric approach. Journal of Productivity Analysis, 3(1-2): 85-101.

GUS. 2001. Agriculture, Hunting and Fishery - Yearbook 2001. Central Statistical Office, Warsaw.

Latruffe, L. 2004. Farm Technical Efficiency, Credit and Investment in a Transition Country: A Microeconomic Analysis in Poland. PhD Thesis, University of Paris 10. Unpublished.

OECD. 2004. Economic survey - Poland 2004. Paris, OECD. 
Piesse, J., Thirtle, C., Hadley, D. 2004. Current and Historic Relative Agricultural Productivity and Performance: Sector and Farm Level. Chapter 1 in Impact on UK of Increasing Agricultural Productivity in New Member States, Report for DEFRA, Project No. EPES 0203/4. Unpublished.

Simar, L., Wilson, P. 1998. Sensitivity analysis of efficiency scores: How to bootstrap in nonparametric frontier models. Management Science, 44(1): 49-61.

Simar, L., Wilson, P. 1999. Estimating and bootstrapping Malmquist indices. European Journal of Operational Research, 115: 459-471.

Simar, L., Wilson, P. 2000. Statistical inference in nonparametric frontier models: The state of the art. Journal of Productivity Analysis, 13(1): 49-78.

Simar, L., Wilson, P. 2005. Estimation and inference in two-stage, semi-parametric models of production processes. Journal of Econometrics, in press.

Tortosa-Ausina, E., Grifell-Tatje, E., Armero, C., Conesa, D. 2003. Sensitivity Analysis of Efficiency and Malmquist Productivity Indices: An Application to Spanish Savings Banks. Centre for Applied Economic Research Working Paper 2003/02, University of New South Wales.

Umetsu, C., Lekprichakul, T., Chakravorty, U. 2003. Efficiency and technical change in the Philippine rice sector: A Malmquist total factor productivity analysis. American Journal of Agricultural Economics, 85(4): 943-963.

Zawalinska, K. 2003. The Competitiveness of Polish Agriculture in the Context of Integration with the European Union. PhD Thesis, University of Warsaw. Unpublished. 
Table 1: Inference results for Malmquist productivity indices; 1996-2000 average

\begin{tabular}{l|c}
\hline Malmquist index average & $-2 \%$ \\
\hline Bias corrected Malmquist index average & $-4 \%$ \\
\hline Confidence intervals & \\
Upper bound average & $+18 \%$ \\
Lower bound average & $-31 \%$ \\
Width average & $48 \%$ \\
\hline
\end{tabular}

Table 2: Regression of Malmquist productivity indices (standard OLS)

\begin{tabular}{l|cccc} 
& Parameter estimates & Standard errors & $t$-test & \\
\hline Land area & $1.3610-4$ & $1.7810-4$ & 0.76 & \\
Capital to labour ratio & $-6.2010-6$ & $1.7810-6$ & -3.49 & $* * *$ \\
Share of hired labour & $-2.7810-4$ & $6.4810-4$ & -0.43 & \\
Share of commercialised output & $3.7310-3$ & $0.3110-3$ & 12.0 & $* * *$ \\
Share of other income & $1.7610-3$ & $0.3810-3$ & 4.64 & $* * *$ \\
Age & $9.3110-5$ & $20.410-4$ & 0.45 & \\
Agricultural education dummy & $1.4710-2$ & $1.4510-2$ & 1.01 & \\
Year 96-97 dummy & 1.06 & 0.017 & 62.9 & $* * *$ \\
Year 97-98 dummy & 0.88 & 0.016 & 53.6 & $* * *$ \\
Year 98-99 dummy & 0.98 & 0.016 & 61.3 & $* * *$ \\
Year 99-00 dummy & 0.99 & 0.016 & 61.6 & $* * *$ \\
\hline
\end{tabular}


Table 3: Regression of Malmquist productivity indices accounting for sampling variability and serial correlation

$$
\text { Parameter estimates Standard errors } t \text {-test }
$$

\begin{tabular}{lccccc}
\hline Land area & $4.9710-5$ & $16.310-5$ & 0.31 & \\
Capital to labour ratio & $-8.8110-7$ & $15.310-7$ & -0.58 & \\
Share of hired labour & $-1.2010-3$ & $0.5410-3$ & -2.22 & $* *$ \\
Share of commercialised output & $-4.9510-4$ & $3.9210-4$ & -1.26 & \\
Share of other income & $-6.6010-4$ & $3.0710-4$ & -2.15 & $* *$ \\
Age & $7.5410-5$ & $16.410-5$ & 0.46 & \\
Agricultural education dummy & $5.3510-3$ & $10.410-3$ & 0.52 & \\
Year 96-97 dummy & 1.02 & 0.014 & 70.8 & $* * *$ \\
Year 97-98 dummy & 0.88 & 0.014 & 65.4 & $* * *$ \\
Year 98-99 dummy & 0.97 & 0.013 & 75.9 & $* * *$ \\
Year 99-00 dummy & 0.98 & 0.014 & 71.5 & $* * *$ \\
\hline
\end{tabular}

Serial correlation parameter: $\rho=-0.42$

Heteroscedasticity parameter: $\tau=43.6$; confidence interval $=[26.0 ; 61.2]$ 